\title{
Cardiogenic shock - a look at acute functional mitral incompetence
} \author{
A J Steyn, ${ }^{4} \mathrm{MB} \mathrm{ChB}, \mathrm{FCA}$ \\ ${ }^{1}$ Department of Anaesthesiology, Rob Ferreira Hospital, Nelspruit, South Africa \\ ${ }^{2}$ Intensive Care Unit, Rob Ferreira Hospital, Nelspruit, South Africa \\ ${ }^{3}$ Rob Ferreira Hospital, Nelspruit, South Africa \\ ${ }^{4}$ Private Practice, Nelspruit, South Africa
}

F A Steyn, ${ }^{1} \mathrm{MB}$ ChB, DA (SA); J Vosloo, ${ }^{2} \mathrm{MB}$ ChB, Cert Crit Care (Surg), FCS (SA), FCS (SA); H Naude, ${ }^{3}$ MB ChB, MMed (Thor);

Corresponding author: J Vosloo (joann.vosloo@gmail.com)

A 44-year-old man presented with cardiogenic shock secondary to acute functional mitral incompetence as well as septic shock related to pneumonia. The patient deteriorated haemodynamically despite adequate medical therapy. An echocardiogram revealed a massive mitral incompetence and an ejection fraction of $32 \%$. An intra-aortic balloon pump was placed and the patient improved dramatically. On day 6 after admission the echocardiogram was repeated, revealing a mild mitral incompetence and an ejection fraction of $58 \%$.

S Afr Med J 2016;106(8):789-791. DOI:10.7196/SAMJ.2016.v106i8.10283

\section{Case report}

A 44-year-old man presented to an emergency room, complaining of acute breathlessness that had started that day. Further questioning revealed a 3-day history of diarrhoea and a 7-month history of a productive cough with bloodstained sputum. The patient reported having had fevers and night sweats for an uncertain period of time. $\mathrm{He}$ was a known hypertensive, for which he was on treatment. He had never been tested for HIV and had no known allergies. In terms of social habits, he reported being a casual smoker for the past 20 years. The only previous surgical exposure was an explorative laparotomy for a stabbed abdomen.

The general examination revealed an acutely ill patient. His fingers were clubbed; he was not pale but perspiration was noted on the face and chest. The vital signs on presentation were a heart rate of a $160 \mathrm{bpm}$, a blood pressure of $88 / 41 \mathrm{mmHg}$ and a respiratory rate of 40 breaths per minute. Pulse oximetry readings showed a saturation of $88 \%$ on room air. The cardiovascular system examination revealed a rapid, weak pulse that appeared regular. There was no parasternal heave and the apex was not displaced. The jugular venous pressure was elevated. Auscultation revealed a gallop rhythm, but no murmur could be identified. The respiratory system examination showed diffuse crepitation on the left and amphoric breathing over the right lower lobe.

The differential diagnosis was given as pneumonia, pulmonary embolus or ruptured pulmonary abscess with a pneumothorax.
The possibility of an acute myocardial infarction was also considered.

A chest radiograph (Fig. 1) revealed right lower lobe consolidation and an electrocardiogram (ECG) showed an atrial flutter. No ECG changes suggestive of ischaemia, such as ST-segment abnormalities or T-wave inversions, were present. A $6 \mathrm{mg}$ dose of adenosine was administered with no effect, followed by a $12 \mathrm{mg}$ bolus, which led to a 5 -second asystole. The asystole converted to sinus rhythm, which became a supraventricular tachycardia of $140 \mathrm{bpm}$. The blood pressure remained low at $78 / 60 \mathrm{mmHg}$. The biochemical work-up did not reveal any abnormalities except low magnesium levels and raised inflammatory markers.

The patient was intubated and admitted to the intensive care unit (ICU). Despite administration of a dobutamine and phenylephrine infusion, the blood pressure remained low at $80 / 60 \mathrm{mmHg}$ and perfusion was inadequate, the lactate level increasing from 2.2 to $3.3 \mathrm{mmol} / \mathrm{L}$.

An amiodarone infusion was started, as it was reasoned that the fast heart rate was contributing to the poor perfusion. The blood pressure improved marginally, but the patient started sweating profusely as the pulse slowed.

Empirical antibiotic cover with ceftriaxone was started in response to raised C-reactive protein (CRP) markers $(52 \mathrm{mg} / \mathrm{L})$ and the clinical and radiological evidence of pneumonia.

An echocardiogram revealed massive mitral regurgitation and a left ventricular

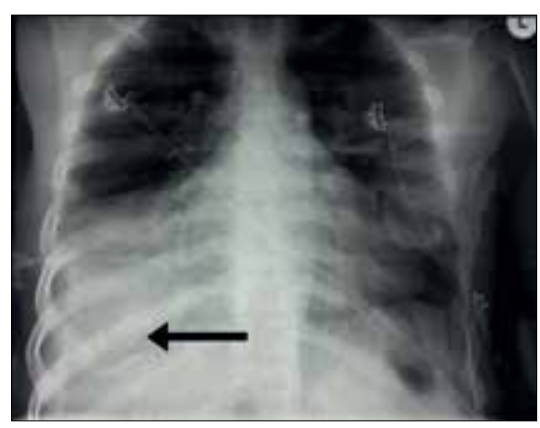

Fig. 1. Chest radiograph showing right lower lobe consolidation (arrow).

ejection fraction of $32 \%$. Decreased movement of the posterior wall of the left ventricle and the interventricular septum was noted. The left atrium was dilated, with a left atrial aortic outflow tract ratio of 2.1:1. The left ventricle was normal in size, while the right atrium and ventricle were also dilated. Right ventricular and right atrial dilatation were present with a normal-sized left ventricle. The vena cava collapsibility index was $<5 \%$.

Furosemide at a dose of $1 \mathrm{mg} / \mathrm{h}$ was started, to reduce the preload. The serum lactate level had increased to $4.4 \mathrm{mmol} / \mathrm{L}$ and urine output had dropped below $0.5 \mathrm{~mL} / \mathrm{kg}$. The pulse pressures remained low and the patient continued sweating. In consultation with the cardiothoracic specialist, it was decided to place an intra-aortic balloon pump (IABP). The decision was based on the poor tissue perfusion despite optimal inotropes (dobutamine). The IABP was placed on day 1 of ICU care. 
The IABP was started on a 1:1 ratio and the haemodynamics improved immediately. The blood pressure improved to $105 / 70 \mathrm{mmHg}$ and the pulse rate varied between 100 and $115 \mathrm{bpm}$. The lactate levels started to decrease, urine output increased and the patient stopped sweating. The dobutamine was weaned to a quarter of the pre-IABP dose within 24 hours and the phenylephrine stopped. On the morning of day 3 , the antibiotic treatment was upscaled to include imipenem, as the inflammatory markers had deteriorated (procalcitonin $100 \mathrm{ng} / \mathrm{mL}$ and CRP $336 \mathrm{mg} / \mathrm{L}$ ). The dose of furosemide was decreased to $0.5 \mathrm{mg} / \mathrm{h}$.

Power, generator and equipment failures meant that the IABP had to be urgently removed on the evening of day 3 . Fortunately, the patient could be maintained on low-dose dobutamine. He was extubated the next day (day 4), and his haemodynamic measurements and perfusion parameters were normal. He was kept in the ICU until the following day, when he was discharged to the ward. An echocardiogram was repeated 5 days after the initial one, which was 1 day after discharge from the ICU, and revealed minimal mitral regurgitation and improvement in the ejection fraction to $58 \%$, with normal septal and posterior wall movement.

From a cardiovascular perspective, the patient was stable and out of danger. Furthermore, it was established that he was HIVpositive with a CD 4 count of 129 cells/ $\mu \mathrm{L}$. The work-up for pneumonia was disappointing, with negative results from cultures, for acidfast bacilli and from GeneXpert. Initial blood cultures contained a Clostridium species, but follow-up blood cultures had no growth after a week. The septic markers (Table 1) dropped dramatically with the change of antibiotics to imipenem.

\section{Discussion}

\section{Acute severe mitral incompetence}

Acute mitral incompetence in patients with cardiogenic shock has an observed mortality of $55 \%$, which is marginally improved to $39 \%$ in patients selected for emergency surgery. Severe mitral incompetence affects about $7 \%$ of patients with cardiogenic shock. ${ }^{[1,2]}$

Acute mitral incompetence can be classified as organic or functional. Organic causes result in physical disruption of the valve, while functional incompetence results from abnormalities of the left ventricle. The causes of acute mitral incompetence are listed in Table 2.

Differentiation between the two groups is very important, as organic causes are usually treated surgically and functional causes can be managed supportively, with medication and the use of an IABP while the underlying cause is addressed. ${ }^{[1]}$

\section{Pathophysiology of acute mitral incompetence}

Acute mitral incompetence differs from chronic incompetence in that there is no time for remodelling. ${ }^{[1,3]}$ The stroke volume is decreased, which can be due to ventricular dysfunction as well as retrograde flow from the left ventricle into the left atrium. ${ }^{[1-3]}$ The decreased stroke volume is compensated for by tachycardia in an effort to maintain cardiac output. When compensation fails, the patient will present with hypotension and end-organ failure presenting as cardiogenic shock. ${ }^{[1,2]}$

The regurgitation into the left atrium results in raised left atrial pressures and pulmonary wedge pressures that lead to pulmonary oedema. ${ }^{[1-3]}$ Numerous cases have been reported presenting with unilateral pulmonary oedema, usually on the right side and confined to the upper lobe. ${ }^{[3,4]}$
This is often confused with pneumonia. ${ }^{[4]}$ Symptoms are related to the fraction of the stroke volume that is regurgitated. Regurgitation of $<30 \%$ of the stroke volume usually presents with mild symptoms, 30 $60 \%$ regurgitation with moderate symptoms, and regurgitation of $>60 \%$ with severe symptoms.

\section{Differentiating between acute and chronic mitral incompetence}

A combination of pulmonary cardiac catheter measurements and ultrasonography is used to differentiate between acute and chronic mitral regurgitation. The difference in findings is based on the time for compensation. Table 3 summarises the basic differences. ${ }^{[1]}$

\section{Clinical presentation}

The usual triad of dyspnoea, haemodynamic instability and shock is not always present in patients with acute mitral incompetence. ${ }^{[1]}$ Auscultation can be misleading, as the new murmur may be subtle and masked by the compensatory tachycardia. ${ }^{[1]}$ However, the

Table 1. Blood results

\begin{tabular}{llllllll}
\hline & $\mathbf{1 0 / 2 / 1 5}$ & $\mathbf{1 1 / 2 / 1 5}$ & $\mathbf{1 2 / 2 / 1 5}$ & $\mathbf{1 3 / 2 / 1 5}$ & $\mathbf{1 4 / 2 / 1 5}$ & $\mathbf{1 5 / 2 / 1 5}$ & $\mathbf{1 7 / 2 / 1 5}$ \\
\hline $\begin{array}{l}\text { White cell count } \\
\left(\times 10^{9} / \mathrm{L}\right)\end{array}$ & 5.5 & 11.9 & 9.9 & 10.7 & 10.7 & 9.6 & 7.6 \\
CRP (mg/L) & 52 & 227 & 336 & 200 & 120 & 77 & 26 \\
$\begin{array}{l}\text { Procalcitonin } \\
(\mathrm{ng} / \mathrm{mL})\end{array}$ & - & 100 & 100 & 77 & 43 & 19 & 3
\end{tabular}

Table 2. Causes of acute mitral incompetence ${ }^{[1,2]}$

\begin{tabular}{ll}
\hline $\begin{array}{l}\text { Organic causes of acute mitral } \\
\text { incompetence }\end{array}$ & $\begin{array}{l}\text { Functional causes of acute mitral } \\
\text { incompetence }\end{array}$ \\
\hline $\begin{array}{l}\text { Leaflet perforation or chordae tendineae } \\
\text { rupture from endocarditis }\end{array}$ & $\begin{array}{l}\text { Dilated cardiomyopathy leads to leaflet } \\
\text { tethering }\end{array}$ \\
$\begin{array}{l}\text { Chordal rupture in myxomatous valvular } \\
\text { disease }\end{array}$ & $\begin{array}{l}\text { Acute ischaemic akinesis of wall segments and } \\
\text { papillary muscle dysfunction }\end{array}$ \\
$\begin{array}{l}\text { Papillary muscle rupture due to myocardial } \\
\text { infarction }\end{array}$ & Takotsubo's cardiomyopathy \\
Prosthetic valve dysfunction due to endocarditis &
\end{tabular}

Table 3. Differentiating between acute and chronic mitral regurgitation

\begin{tabular}{lll}
\hline & $\begin{array}{l}\text { Chronic mitral } \\
\text { regurgitation }\end{array}$ & $\begin{array}{l}\text { Acute mitral } \\
\text { regurgitation }\end{array}$ \\
\hline Cardiac output & Normal & Decreased \\
Ejection fraction & Increased & Normal or decreased \\
Left ventricular size & Increased & Normal \\
Left atrial compliance & Normal & Normal \\
Left ventricular end-diastolic pressure & Normal & Markedly increased
\end{tabular}


Table 4. Echocardiographic findings in acute mitral regurgitation ${ }^{[2]}$

\begin{tabular}{llll}
\hline & Mild & Moderate & Severe \\
\hline Regurgitant volume $(\mathrm{mL} /$ beat $)$ & $<30$ & $30-59$ & $\geq 60$ \\
Regurgitant fraction $(\%)$ & $<30$ & $30-49$ & $\geq 50$ \\
Effective regurgitant orifice area $\left(\mathrm{cm}^{2}\right)$ & $<0.20$ & $0.20-0.39$ & $\geq 0.40$ \\
Vena contracta width $(\mathrm{cm})$ & $<0.30$ & & $\geq 0.70$
\end{tabular}

murmur, when identified, is pansystolic and best heard at the apex of the heart with the patient in the lateral decubitus position. ${ }^{[2]}$ When the afterload is increased, for example by strong hand grip or squatting, the murmur is accentuated. Using similar logic, the intensity of the murmur is decreased by standing and the valsalva manoeuvre. ${ }^{[2]}$ Tachypnoea and associated pulmonary oedema can further increase the difficulty of auscultation. Any signs that could suggest myocardial infarction should prompt thorough investigation, as this remains the most common cause of acute mitral regurgitation. ${ }^{[1]}$ Patients presenting with fever in association with the above signs should be worked up for infective endocarditis.

As the clinical signs of acute valvular pathology are not always obvious, a high index of suspicion should be maintained. If acute valvular pathology is suspected, the patient should receive an ECG, chest radiograph and echocardiography. ${ }^{[1,2]}$ The echocardiographic findings that determine the severity of mitral regurgitation are summarised in Table 4.

Transoesophageal echocardiography (TEE) provides a more detailed view and should be used if endocarditis or valvular thrombi are suspected. ${ }^{[2]}$ The use of TEE has become increasingly important in the assessment of mitral incompetence as it is highly specific and sensitive for numerous causes and helps to localise the problem area with more precision. It is essential in the planning of surgical intervention. ${ }^{[1,2]}$ In patients with pulmonary artery catheters in situ, moderate and severe mitral incompetence can be recognised by a large $\mathrm{v}$ wave and a rapid y descent. ${ }^{[2]}$

The routine blood tests should include a full blood count, electrolyte profile and urea, and creatinine should be tested together with troponin and B-type natriuretic peptide (BNP) levels. ${ }^{[1,5]}$

\section{Management of acute mitral incompetence}

The general management of acute mitral incompetence includes reducing afterload and maintaining a fast-normal heart rate $(80$ $100 \mathrm{bpm}$ ). Care should be taken to prevent sudden increases in afterload, for example, during intubation and surgical stimulus, as this will increase the regurgitation fraction.

In the management of acute mitral incompetence with an organic cause, supportive therapy can stabilise patients long enough to prepare the operating suite. Medical therapy is not a substitute for surgical intervention in these patients. Valve repair or replacement is the definitive treatment, while the use of dobutamine, nitroprusside and nitroglycerine are temporary measures. The use of an IABP may be beneficial in these patients. Surgical treatment is reserved for patients with a regurgitant fraction $>30 \%$. Whenever possible, valve repair is preferred to replacement as the prognosis is better and anticoagulants are not needed. ${ }^{[1,3]}$

In the management of acute mitral incompetence with functional causes, supportive therapy may be sufficient and surgical intervention not required unless initial supportive measures fail. The aim is to optimise the perfusion of the heart and thus the affected area. The use of an IABP is effective in all cases of functional mitral incompetence, and this is especially true for cases of myocardial ischaemia or cardiomyopathy. ${ }^{[1,3]}$

\section{Prognosis}

There are limited studies on the prognosis of patients with acute mitral incompetence. Numerous studies have been done on increased mortality from ischaemic mitral incompetence following myocardial infarction and the presence of mitral incompetence post-infarction is a poor prognostic sign. ${ }^{[6]}$ Studies on the prognosis of acute functional mitral incompetence are few and none have ventured to assign values to mortality. Studies have shown that the degree of left ventricular dysfunction is not proportionate to the severity of the mitral incompetence and it is therefore impossible to draw accurate correlations between severity and outcome. ${ }^{[7]}$ Functional mitral regurgitation is a poor prognostic sign in left ventricular dysfunction caused by cardiomyopathy or ischaemic disease. ${ }^{[7]}$

BNP measurement is being used increasingly as a prognostic tool. Its use in relation to functional mitral incompetence has not been specifically studied. A correlation between a raised BNP level and an increased number of adverse events under conservative management has been observed. BNP measurement should be used in conjunction with other risk stratification tools and clinical evaluation. ${ }^{[5]}$

Aggressive early surgical management of patients with acute organic mitral incompetence has been shown to decrease mortality. ${ }^{[1]}$

\section{Conclusion}

The incidence of acute functional mitral incompetence is dwarfed by the incidence of acute organic mitral incompetence. However, it is important to exclude acute functional mitral incompetence, which has markedly different management to and much lower morbidity and mortality than acute organic mitral incompetence.

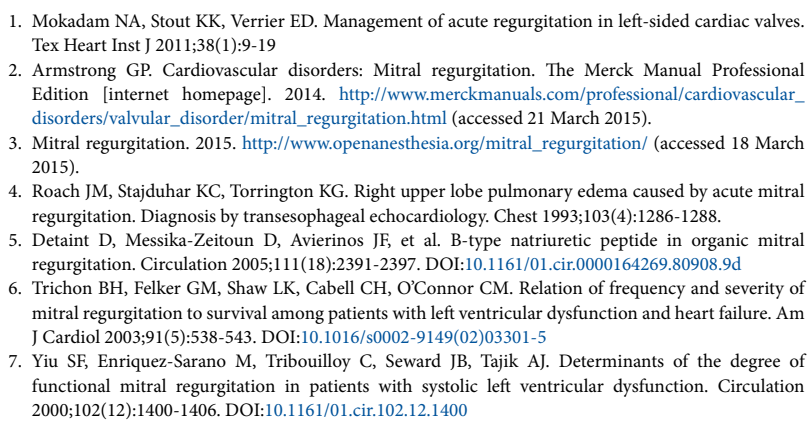
Tex Heart Inst J 2011;38(1):9-19

2. Armstrong GP. Cardiovascular disorders: Mitral regurgitation. The Merck Manual Professional Edition [internet homepage]. 2014. http://www.merckmanuals.com/professional/cardiovascular disorders/valvular_disorder/mitral_regurgitation.html (accessed 21 March 2015).

3. Mitral regurgitation. 2015. http://www.openanesthesia.org/mitral_regurgitation/ (accessed 18 March 2015).

. Roach JM, Stajduhar KC, Torrington KG. Right upper lobe pulmonary edema caused by acute mitral regurgitation. Diagnosis by transesophageal echocardiology. Chest 1993;103(4):1286-1288.

5. Detaint D, Messika-Zeitoun D, Avierinos JF, et al. B-type natriuretic peptide in organic mitral regurgitation. Circulation 2005;111(18):2391-2397. DOI:10.1161/01.cir.0000164269.80908.9d

6. Trichon BH, Felker GM, Shaw LK, Cabell CH, O'Connor CM. Relation of frequency and severity of mitral regurgitation to survival among patients with left ventricular dysfunction and heart failure. Am mitral regurgitation to survival among patients with left ventricular d

7. Yiu SF, Enriquez-Sarano M, Tribouilloy C, Seward JB, Tajik AJ. Determinants of the degree of Yiu SF, Enriquez-Sarano M, Tribouilloy C, Seward JB, Tajik AJ. Determinants of the degree of
functional mitral regurgitation in patients with systolic left ventricular dysfunction. Circulation 2000;102(12):1400-1406. DOI:10.1161/01.cir.102.12.1400

Accepted 9 November 2015 